\title{
Eisejuaz: chamanismo y cevil (fragmento)
}

\section{Eisejuaz: shamanism and cevil (fragment)}

\author{
Enrique Flores \\ Universidad Nacional Autónoma de México \\ adugobiri@gmail.com
}

Resumen: Este trabajo es un fragmento de un libro en proceso de publicación: Eisejuaz, chamán. Gérmenes y materiales. Aborda la novela Eisejuaz, de Sara Gallardo, ignorada hasta hace pocos ańos y obra maestra marginal que se sumerge en el universo y el habla del pueblo wichí, a través de su protagonista, Eisejuaz -imaginario o ficticio, pero en su origen muy real-, cuyos vínculos con el antiguo chamanismo no se disociaban por entero de las acciones de los llamados "chamanes de Dios", y sobre todo - a través de la figura de Santos Aparicio, o "Vicente Aparicio" en la novela-, con la intervención del cebil, la planta "alucinógena”.

Palabras clave: Eisejuaz, Sara Gallardo, Chamanismo wichí, Chamanes de Dios.

Abstract: This work is a fragment of a book in publication process: Eisejuaz, chamán. Gérmenes y materiales. It addresses the novel Eisejuaz, by Sara Gallardo, few knew until a few years ago and a marginal masterpiece that immerses itself in the universe and speech of the Wichí people, through its protagonist, Eisejuaz -imaginary or fictional, but in its origin very rea-, whose links with ancient shamanism were not entirely 
dissociated from the actions of the so-called "Shamans of God", and above all -through the figure of Santos Aparicio, or "Vicente Aparicio" in the novel-, with the intervention of cebil, the "hallucinogenic" plant.

Keywords: Eisejuaz, Sara Gallardo, Wichí Shamanism, Shamans of God.

Recibido: 2 I de enero de $202 \mathrm{I}$ Aceptado: I 5 de marzo de $202 \mathrm{I}$ https://dx.doi.org/IO.I 5 I74/rv.vi3i28.60I

El vegetal se vengaba del hombre. Construia dentro de él un árbol que extendia sus hojas en las evaporaciones cerebrales. Pendía de ese árbol irreal, en el que cantaba.

José LeZama Lima, ARTAUD Y EL PEYOTL

\section{$\mathrm{E}$} cevil o hatah-cebil, hatax o jatáj, curupay o curupai, huilca o vilca, cohoba, yupa, paricá, son algunos otros nombres suyoses el alucinógeno empleado por los chamanes wichís. Su desaparición se vincula a la progresiva extinción del chamanismo en el pueblo de Eisejuaz. ${ }^{1}$ El cevil, Anadenanthera colubrini, es una mimosa arborescente que alcanza una altura de hasta veinte metros y de cuyas semillas se extrae, moliéndolas, un rapé muy potente para inhalar a través de tubos de caña o de hueso de animal con un pico de ave en el extremo para introducirse en la nariz. ${ }^{2}$ El "viaje cha-

${ }^{1}$ Sobre Eisejuaz, la novela de Sara Gallardo, y "el verdadero Eisejuaz", $c f$. mi trabajo: "Eisejuaz: chamán".

${ }^{2}$ La información acerca del cevil proviene principalmente del trabajo de María Cristina Dasso y Guadalupe Barúa sobre el cevil y el chamanismo wichí. Tam- 
mánico" sería el efecto principal de la inhalación ceremonial del polvo, aunque pueden acompañarla, aparte de la embriaguez, el furor, el mareo, los vómitos, la euforia, el éxtasis y la exuberancia. Esos efectos pueden durar unos veinte minutos, lo que marca el ritmo de los lapsos de la aspiración del rapé en la ceremonia, pero si se fuma-como sucede en el marco proletarizado de Eisejuaz-los mismos efectos duran ese mismo tiempo, aunque con un efecto remanente más duradero.

El cevil es "un vegetal de uso exclusivamente chamánico" y se le visualiza como permanente donación de los atributos celestes, a través de los “espíritus de la vegetación” (Dasso / Barúa: 222). La elección o iniciación del chamán sucede de la siguiente manera:

Estos seres poderosos, no humanos, que en el Bermejo medio llaman ahot, usualmente llevan a cabo su elección del candidato a hayawé -chamán- secuestrándolo mediante una suerte de enfermedad súbita o repentino debilitamiento durante el cual el individuo es llevado al monte cerrado, o debajo de la tierra, o al interior del tronco de un árbol, donde los seres ahot tienen su morada. En ese estado, los seres ahot se dejan ver y le seńalan a diversos entes causantes de enfermedades. El candidato observa todo lo que le rodea, $[y]$ aprende los cantos y aromas de los que serán sus espíritus auxiliares, towehei (Dasso / Barúa: 219-220).

Dasso y Barúa nos ofrecen una estupenda descripción de la ceremonia del hatah, durante la cual los chamanes ingieren el psicotrópico, en el nisar o la inhalación del cevil. Como en castellano a veces se le llama misa, se ha asociado ambas liturgias a partir

bién me referiré a la investigación etno-neuropsiquiátrica, menos accesible, de Pagés Larraya (autor de Lo irracional en la cultura), titulada: "La cultura del paricá”. 
de su cercanía con la palabra castellanizada nisar, 'aspirar rapé, y de la semejanza "gestual" de la ceremonia: "la concelebración, la oración y el canto". La ceremonia se celebra en torno a una "mesa ritual", cargada de objetos rituales: las "bolsas de los chamanes", las sonajas tolánek, los cascabeles chilihtáh, el membranófono to pim, el plumero wonlhóh'ulé, y por fin el vino y la bolsa de hatah molido para compartir. El rito se inicia al amanecer y tiene dos o más horas de duración, con los chamanes mirando siempre en dirección al noroeste:

Tras una primera aspiración del cevil, el chamán principal comienza a convocar a los auxiliares con el golpe de to pim y ritmo acompañante de chilihtáh o cascabeles en la mano con la que sostiene el membráfono. Su canto carece de texto, ya que modula sonidos sin pronunciar palabras. El canto es acompañado por los chamanes participantes, que han ingerido por sus narices el cevil, y todos seguirán haciéndolo con regularidad, en lapsos de alrededor de quince minutos. Los cantos se acompasan y desacompasan individualmente, y los chamanes manifiestan una diferente reacción y consumo del mismo.

Transcurridas unas vueltas en torno de la mesa y los demás participantes, el chamán irá haciendo sonar el tohúl-flauta de hueso de yulo [o cigüeńa] - con largos silbidos separados por silencios, siendo seguido sucesivamente por los demás. El alma del chamán se cree que sale por el tohúl, que posibilita su desprendimiento y ascenso, donde se mete en el ave que le permitirá volar y ver el mundo desde esta perspectiva aérea. Sigue una prolongada performance de canto, instrumentos y plumereado mutuo con plumas de suri -ñandú-, hasta que se llega al clímax de canto e instrumentos, continuo, luego decreciendo, sin más ingestas de cevil, hasta finalizar con las sesiones de curación de los individuos o grupos que acuden a tal fin (Dasso / Barúa: 221-222). 
En las ensoñaciones del hatah, se manifiesta "una atmósfera transformada", casi onírica - "los hechos ocurren como en sueños"-, de embriaguez y desorientación, como "variaciones de eventos" chamanísticos y mitológicos que involucran al puma y al jaguar, "el camino que se abre, la casa en el árbol, la gente habitando adentro, la conducta de los dueños y la iniciación chamánica”. "Las aves son el anuncio y los custodios de esta senda al hogar que es un árbol, el palo borracho". El sońador "se emborracha y se siente lleno, y es incapaz de reconocer las cercanías de su casa”. "La iniciación chamánica es presentada como una expedición de caza y de recolección de miel” (Dasso / Barúa: 226-227). Del río Pilcomayo a la muerte de los cazadores-recolectores, todos los ecos resuenan en Eisejuaz.

\section{[ Escena 4: Aparicio y Eisejuaz ]}

Eisejuaz camina "desde el ingenio hasta Orán". Es el ingenio de San Martín del Tabacal, legendario establecimiento presidido por el poderoso patriarca Robustiano Patrón Costas, situado al sur de Embarcación y en el camino a la ciudad de Orán, cuyo éxito económico se fundó sobre el trabajo forzado de los pueblos nativos provenientes de las riberas del río Pilcomayo, bajo un régimen de "enganche" que aplicaba una doble táctica de "atracción y coacción” para someter o esclavizar a sus trabajadores. Eisejuaz entra a Orán y ve que las calles "estaban rotas" y "abiertas las venas que llevan el agua de las ciudades", como para cumplir la profecía enunciada por el indio "mataco": "Rómpase mi superficie, mi cáscara, mi corteza, para que pueda beber del agua de los mensajeros, que brota desde el centro de mi corazón”. Porque, como dice el peregrino, "allí los hombres trabajaban y golpeaban el suelo de las calles. Y los caños del agua, que deben ser secretos, se veían” (Eisejuaz: 62). 
"Yo caminé hasta la casa de Aparicio", dice entonces Eisejuaz. "Nada dijo de mi bastón ni de mi aspecto ni de mi desnudez. Me vio parado en la calle, habló a su mujer, y salió a la calle. Y caminamos en la bruta calor". Ahí la entrada del mataco a Nueva Orán; las preguntas del hombre-tigre sobre el silencio de las voces y la pérdida de la revelación. El conjuro invoca al "Tigre”, al "anciano" y al chamán: "Ayó, Tigre, Vicente Aparicio, el hombre anciano, y yo, Eisejuaz, Éste También, el comprado por el Señor” (Eisejuaz: 63):

— ¿A dónde se han ido todos esos que recibiste?

— ¿A dónde? No sé.

-Los mensajeros de la sangre caliente y de la sangre fría? ¿A dónde?

—No sé.

Los mensajeros se han ido, nada más; no se sabe a dónde, el silencio no se puede interrumpir. Eisejuaz, o su otro nombre - "Éste También", y hay otro: "Agua que corre", ambos secretos-, es el "elegido", "el comprado por el Señor". Ahí donde vuelve el cevil, en esa escena alucinante en que se acercan, solos, Eisejuaz y Aparicio, a la luz del cevil:

En la bruta calor, llegamos a un lugar donde hay algunos árboles, y nos sentamos para esperar la noche. Cuando vino la noche busqué en mi pantalón unas semillas de cevil y se las di. Él se quitó un zapato y las puso adentro. Buscamos una piedra, un fierro, y encontramos un pedazo de la calle rota, un cacho de piedra. Y molió las semillas de cevil. Mezcló ese polvo con el tabaco. Y armó un cigarrillo. Y me miró, pero yo ya no tenía mi yesquero. Entonces encendió el cigarrillo. Su alma salió de recorrida. Cantó (Eisejuaz: 63). 
La escena corresponde a una especie de sesión chamánica, de trance y curación, aunque en un ámbito urbano o suburbano, más proletario que selvático - "un lugar donde hay algunos árboles”, en donde esperan la noche-. Con "un pedazo de la calle rota", con "un cacho de piedra", "El Tigre" muele las semillas del cevil, metidas en un zapato. Todo en silencio. El cevil, pulverizado, se mezcla con tabaco y Aparicio arma un cigarrillo, que le ofrece a Eisejuaz. Pero Eisejuaz ya no tiene su yesquero. Aparicio lo mira, sin hablar, y enciende él mismo el cigarrillo. Ahí, en esa calle de arrabal, ese barrio subproletariado entre desierto e industrial, Aparicio enciende el cigarrillo, fuma. Y la planta empieza a surtir su efecto, que no se describe. Únicamente se dice: "Su alma salió de recorrida". Y "canto":

¿De qué vale la baya, la algarroba del mes de abril? Ya perdió el gusto, ya perdió suavidad, pero ella no eligió la hora de su vida. Debe cumplir. Debe ser molida, alimentar al hombre. Debe caer y sembrarse. Debe cumplir.

¿De qué vale el hormiguero que quedó en el desmonte, donde la tierra es negra, donde pondrán la caña? ¿De qué vale? La hormiga mira lejos y ve negro. No hay hojas, no hay pastos. Debe cumplir. No eligió la hora de su vida. No eligió su lugar.

No eligió. No eligió. Debe cumplir. Oh, no eligió. Debe cumplir.

Se ha dicho: esos chiriguanos ofrecieron mistol, algarroba. Devolvieron favores. Esos matacos dejados, torpes, brutos, pidieron vino, pidieron alcohol, sólo saben pedir.

No eligió. No eligió. Debe cumplir. No eligió (Eisejuaz: 63)

La forma ideada en Eisejuaz para asumir o sostener el canto ritual, chamánico, o de trance, consiste en acudir a formas bíblicas, al espíritu y la fórmula ceremonial, y aquí a la parábola, al lengua- 
je alegórico, trasunto de la divinidad. En relación a la sustancia del canto, lo que parece expresarse en él es el cumplimiento del destino y al mismo tiempo la elección -en el caso particular de Eisejuaz, el cumplimiento de la elección, la obligación del don, de la visión, de la revelación, como destino, la asunción fatal y purgatorial, de la culpa y la redención-. Pero se filtra, asimismo, en un sentido más histórico, como de fin de mundo, un oscuro futuro que se arrastra desde el pasado, negro, aciago, un destino, un tiempo de destrucción. Un tiempo que, contrastado con el destino chiriguano - pueblo de origen guaraní que pudo reorganizarse en las crueles circunstancias de la colonización-, fue para los "matacos" -término despectivo usado para designar a los wichí, acusados y estigmatizados como vagos y borrachos por el colonizador- un tiempo de humillación.

La esencia del cevil es el canto, y este es el segundo canto del cevil: canto que ya no es onírico, ya no viene en sueños, porque lo inspira física, sustancial, orgánicamente el cevil; canto alterno, a dúo, que los dos fumadores cantan de forma continua / discontinua. Pues, como dice Eisejuaz al término del canto de Aparicio, reiterando el pensamiento, los ritmos de "Ayó" -el chamán-: "He fumado con él, mi alma salió de recorrida, cantô":

En el centro de la tierra está el viborón. Enrosca las raíces del monte. Duerme con ellas. Nadie eligió, oh no, nadie eligió. Ha caído el monte, han muerto los palos, nadie eligió, oh no, nadie eligió, nadie eligió. Sólo ya los palos cantan para Eisejuaz, sólo el aire. Hay que cumplir (Eisejuaz: 64).

"Nadie eligió". Este enunciado designa un destino trágico: el de los "matacos". Y aunque también se refiere al destino -triste- de Eisejuaz, y al don que le fue concedido o al que fue obligado como elegido o "chamán de Dios" - "el comprado por el Señor"-, desig- 
na a la vez lo contrario, doblemente: "nadie eligió" / fue elegido / fue condenado por esa elección. Pero el canto alterno de Eisejuaz supone otras derivaciones y ramificaciones de índole mitológica, como esa alusión al "viborón", serpiente legendaria muy viva en los relatos wichís. ${ }^{3}$ Más aun, Eisejuaz precisa en su canto el tiempo de destrucción al que nos referiríamos: el fin del monte originario y de la vida "salvaje" de los wichís, ese pueblo de cazadoresrecolectores; el fin de los "palos" y la magia, el fin del cevil y de la alucinación y el trance, de los espíritus de la vegetación. Y por último, el doble sentido conflictivo de la fórmula final del canto: "Sólo ya los palos cantan para Eisejuaz, sólo el aire", que dice, a la vez, que ya únicamente los "palos" -que "han muerto" ya, y ya no cantan- "cantan para Eisejuaz", pero también que los "palos" -y en particular, el cevil- ya solo "cantan para Eisejuaz". Lo que significa, además, que los "palos" que "cantan para Eisejuaz" son los "palos que cantan", y a los que cantan, los cantos de Aparicio y Eisejuaz. Cantan a los espíritus: el cevil canta al cevil, y Eisejuaz es su vehículo. Es lo que "hay que cumplir".

El canto se reanuda, y termina: "Ha cantado Ayó, su alma que fue de recorrida”. La parte sustancial regresa a la parábola verbal, la alegoría artesanal, la alfarería figura de la vida y la creación, con la campana de la misiones "gringas" modelando la cotinianidad. Pero el destino vuelve a ser la muerte, la desaparición, porque "nuestro tiempo terminó":

He visto las últimas mujeres que baten el barro, y amasan, vuelven a amasar y forman el botijo, ese que suena como la campana del gringo, ese redondo como la mujer y el hijo. Y ese alto con tres

${ }^{3}$ Cfr. la gran compilación de Antonio Tovar: Relatos y diálogos de los matacos. Sobre el papel principal de Santos Aparicio -modelo de "Vicente Aparicio"- como "informante" de Tovar, Cfr. "Eisejuaz: chamán” y "Eisejuaz, chamán (y relatos de la vida de Santos Aparicio) (Flores, 2020). 
panzas. Y ese chiquito que lleva el agua al monte. Forman el botijo, y tantos hombres van y compran tarros, van y buscan latas. Pero ellas tienen que amasar, tienen que hacer el botijo hermoso, que suene como la campana del gringo. No eligió la hora de su vida, no eligió, oh no eligió; debe cumplir.

No lloremos si nuestro tiempo terminó.

No lloremos, ¿y para qué llorar?

Morimos juntos: el tigre, el monte, los ríos, sueltos como pelos del Señor, y nosotros (Eisejuaz: 64).

No queda más que la resignación, la muerte en vida en que vive un pueblo desde mucho tiempo atrás. “¿Para qué llorar?” "Morimos juntos", canta Aparicio al final, en un acto postrero, y solitario, de comunidad. Comunidad visible e invisible en desintegración: tigres, montes, ríos; animales humanos y no humanos, seres de la naturaleza, espíritus. - "Morimos juntos: el tigre, el monte, los ríos, sueltos como pelos del Señor, y nosotros".

El segundo canto del cevil es un lamento por la muerte del pueblo wichí. Muerte antigua que comienza al dejar el Pilcomayo, con la entrada de colonos en el "monte", con la tala de los bosques y la extinción de la fauna, el desecamiento de los ríos, la reducción, la explotación en los ingenios y los trapiches, las perforaciones petroleras, la expulsión, la migración, el Evangelio. Y el canto, como antes apunté, ya no se canta en la selva sino en esta colonia proletaria a la que ha acudido Eisejuaz en busca de Vicente Aparicio, adonde han salido a la calle y ha extraído las semillas del cevil, bajo unos árboles, en la oscuridad y el silencio, y adonde han molido las semillas, han fumado, han olvidado y han cantado.

Ahí, sentados en la calle, mareados aun y ofendidos por el grito del conductor de un auto que pasa, la escena se clausura con una austera y callada ceremonia de iniciación: 
Paró un auto y han gritado:

— Flor de borrachera! ¡Dejen dormir!

Entonces quedamos callados. Ayó me agarró la mano. Sopló adentro de mi boca. Puso de su saliva sobre mi lengua. Caminamos después volviendo para su casa, y pasamos por las calles abiertas de esa ciudad, sin obreros porque era de noche (Eisejuaz: 64).

\section{[ ESCENA 5: EL FIN DEL MONTE ]}

La que habla en esta escena es "una mujer de los nuestros, mi hermana en el monte". Lo que "canta" es, en una suerte de relato rimado, de saga de los orígenes, de cosmogonía de la expulsión, la partida del río Pilcomayo. Las voces se yuxtaponen: "Se tenemos que ir". Tristes: "Ya en el monte no se puede vivir". "Tantos días a pies, saliendo del Pilcomayo", rememora la vieja. "Pero todos vinieron a morir con la peste del blanco" (Eisejuaz: 100).

La "peste del blanco", literalmente, y no solo de manera figurativa. Su narración se construye poéticamente, en lenguaje figurado, rítmico, formulístico, repetitivo como al comienzo del relato, como en trance: "He comido carne, pan. Como borracha, con sueño, como de vino estoy, para recordar, para hablar lo que vi. Cosas que viste, cosas que vivî". Es la historia rimada del wichí Guanslá y de su mujer churupí o nivaclé en el Pilcomayo:

El hermano de mi padre, ese joven Guanslá. Contento de su mujer linda, de gente churupís. Traída de la guerra, gorda, con buena voz. Cada día se aleja, cada día volvió. Nadie tuvo malicia, nadie desconfió. Su marido contento, nunca la receló. Ha dicho: "Me he dormido". Dijo: "Frutas busqué". Ella tiene hombre suyo, del tiempo de antes, y lo va a encontrar (Eisejuaz: 100). 
El churupí o nivaclé es otro pueblo de las orillas del Chaco Boreal, de las orillas del Pilcomayo, cazadores-recolectores como los wichís, los tobas y los pilagás. La esposa de Guanslá ha sido raptada en una previa incursión armada de la tribu wichí y es parte del botín, y Guanslá a su vez, traicionado por ella, será capturado en la emboscada urdida por los churupís. A este relato "del tiempo de antes" lo definen la prosa rimada y la crueldad:

Una tarde: "Encontré un anta muerta, es fresca, vámosla a buscar". Siete hombres han ido, y el primero Guanslá. Allí los esperaban, matan a cinco, uno puede escapar. El séptimo lo llevan, lo van golpeando, y es Guanslá. Grito me viene ahora, gana de matar. Lo achicharran, lo pinchan, ella se ríe sin parar: con machete chaqueño corta la boca de Guanslá. De puro diente queda, sin risa de verdad. Esa que baila y que le escupe la hombría le va a cortar. Lo pinchan con las flechas, le ponen brasas, no dejan de cantar; la tierra que levantan sobre la sangre se va a pegar. Ya abre su boca rota, ya se muere el alegre Guanslá. Le ha atravesado un ojo: "Te dejo el otro por bondad. Así me ves contenta, contento a mi hombre y después reventás" (Eisejuaz: 100-101).

Conflictos de guerra, tribales, sexuales, se transforman en arquetipos, violencias míticas. Violencia sobre la mujer, y venganza de la mujer. ¿Irrupción del "salvajismo" de los indios ante la mirada -imaginaria, fabulosa, fascinada, aterrorizada, siniestra- de la autora, de la aristócrata porteña? Rituales de guerra: cantos y danzas, tortura y castración. Pero vendrá la contraparte, tras el cambio de rima -de la (á) a la (ó), y al final a la (é)-, como una retribución de la violencia física y simbólica, venganza sexual reproducida casi al infinito, multiplicada en escenas de tortura y crueldad ilimitada, digna de Sade o Bataille: 
Ya viene aquel muchacho, el escondido, el que espió. Ya cuenta lo que ha visto. Tu padre llama, el jefe alza la voz. Mandamos nuestros hombres, pero no hay rastros, esa gente escapó. Al año vino batalla, matamos todos, el mataco venció. A la mujer y al hombre trajeron vivos, quién no los vio. Ya le queman los pechos; mi madre la cuereó; tu madre con tizones su hembraje le quemó. Como tigra gritaba, le arrancamos la piel. Le cortamos las manos, los dedos de los pies. Los perros los tragaban, con bramidos gritó. Al fuego la tiramos, un humo espeso hedió. Al hombre le sacaron todo el pelo y la piel. Vi su cabeza cruda, la colgaba la piel. La sangre que escurría la quería beber (101).

Éxtasis de violencia, éxtasis de crueldad -irreal, fantástico, mitológico, visto en trance-: desollamiento, escalpadura, decapitación, canibalismo, más allá de las fronteras rituales de la transformación animal, de lo no humano y lo inhumano, de la pura, desnuda exclamación animal de dolor -"como tigra gritaba, le arrancamos la piel”-. Y nosotros lo hicimos: "mi madre la cuereó"; "tu madre con tizones su hembraje le quemó". Todo en el marco de una escena o una serie de escenas que un arquetipo del "salvajismo" inspira y remite a un pasado no idílico, no comprendido, sujeto a una "redención" y a una supuesta crueldad originaria expresada a través de un canto ritual y de un relato litúrgico y ritual.

\section{[ Escena 6: Lo Que Se Ve ]}

“¿No era el anunciado?”, se pregunta Eisejuaz, "turbado en el corazón”. “¿No es este el último tramo?”. Es el preámbulo al tercer canto del cevil, tras ańadirse: "Sin respuesta me vi". Y si los cantos chamánicos wichís son sin palabras, puramente sonoros, la invocación de Eisejuaz a los espíritus paganos o cristianos es pura danza, aliento, exhalación: 
Molí semilla de cevil y la fumé para buscar contestación.

Como pajas en el viento, como flechas, como pájaros en el mundo, vi los buenos mensajeros, los malos mensajeros del que es solo, nunca nació, no muere nunca. He cantado allí:

—Eh, eh, eh. Digan. Eh, eh, eh.

Bailé.

—Vengan. Eh, eh, eh. Vengan. Eh, eh, eh. (Eisejuaz: 102)

La "poesía”, la metáfora, el símil está en la descripción, en la "prosa poética" de Eisejuaz. No en el canto, que se remonta a una especie de anterioridad del relato, previa a la recreación literaria, escritural. En el ritmo. En la forma reiterativa, dancística del canto. Formulada a través de preguntas y respuestas, imágenes figuradas, apariciones sucesivas:

Como las moscas sobre el guerrero muerto, como choca y da vueltas el pescado en el agua, como lluvia que brilla, que se mueve, alrededor de mí. Vinieron a mi boca.

Serpiente.

— ¿Qué de mí? Dormía y, ¿qué de mí? Descansé y, ¿qué de mí?

— Vos. Para saber de la callada, de la silbadora, para dónde mi oído, para dónde mi ojo, cómo el cumplimiento aquel.

—Eso lo esperarás. Eso verás.

Caballo.

- ¿Qué de mí? Corría y ¿qué de mí? Golpeaba con mis patas y ¿qué de mí?

-Vos. Para saber, aquí. Del alto, del que tiene el trueno en cada pie, para dónde este oído, cómo será.

—Eso lo esperarás. Eso verás (Eisejuaz: 102-103).

Lengua esotérica, lengua chamánica, lengua de los animales. Conjuro. Lenguaje "cifrado", como diría Hernando Ruiz de Alar- 
cón. Danza, percusión, ebriedad. Invocación sincrética, misturada, al ángel, al tatu, al suri, al rococo, a los palos, a la lluvia, al viento:

He bailado, y golpeé el suelo con mis pies. Como el murciélago en verano, como hojas en el viento frío, alrededor de mí.

-Ángeles mensajeros, busco la palabra del que es solo, no nació, no morirá. Aquí del tatu, cuero de hueso, aquí del suri, buen esquivador, aquí el rococo, escuchador con la garganta, aquí de los palos, mensajeros del Señor. Aquí de la lluvia fuerte y de la que es mansa, del viento grande y de los vientos, mensajeros, ángeles del Señor. Díganme. Cómo es el cumplimiento, cómo será. Cómo vino, como vendrá.

Dando vueltas: "Eso esperarás”. Girando: "Eso verás. Eh, eh, eh. Eso verás” (Eisejuaz: 103).

Profecía y silencio de la revelación -la elección, la anunciación-. Y de vuelta giros, espuma, éxtasis, saliva, ebriedad. El cantador se asume como vehículo - "hablaban por mi boca”-, en trance psíquico y físico -como el sapo rococo, ingrediente peligroso del payé, inductor de alucinaciones, y como él "escuchador con la garganta"-. Y el baile se reanuda, se reitera la repetición, y "revolviéndose, empujándose", impera la sonoridad:

Hablaban por mi boca y la espuma salió de mi boca, mojó mi pecho, mojó el suelo. Hablaban por mi boca y he bailado, golpeé el suelo con mis pies.

Como el mosquito en el pantano, como el gusano, revolviéndose, empujándose.

-Eh, eh, eh. Vos y vos. Eh, eh, eh. Vos y vos.

-Eso lo esperarás. Eso verás. Eh, eh, eh, eso verás (Eisejuaz: 103). 
Ritmo reiterativo. Seres, pueblos apareciendo, del subsuelo, del agua, del monte:

Llamé a los pueblos chicos de bajo tierra. Los hombres chicos el pantano, del agua. Los sin peso que corren por el monte, pueblo chico corredor del monte. Los que andan, los que vigilan, los que roban, los que curan. Como ratones, como bicherío que escapa en la creciente, y no chilla ni habla, corre y no mira, corre y se empuja, así vinieron los pueblos chicos de bajo tierra, del pantano, del agua, y el pueblo corredor del monte.

Hablaron por mi boca.

— ¿Qué es? Descansaba y aquí, ¿qué es? Descansaba y aquí, ¿qué es?

Como buitres moviendo las colas, picando, arrancando, moviendo las cabezas, los pueblos chicos, los hombrecitos corredores, a mis pies. Bailé, el suelo golpeé con mis pies. Y hablaron por mi boca.

—Ya verás, ya verás, ya verás (Eisejuaz: 104).

La escena del canto del cevil lo articula todo: mitología, ritual, chamanismo. La pregunta: “¿qué es, qué es, qué es?”. La respuesta: "Ya verás, ya verás, ya verás". Vuelve el ritmo ritual, y vuelve asimismo la voz, surgen más voces en la voz, afuera, por encima, por dentro, como un flujo continuo o fuente incesante del ritmo: "Hablaron por mi boca". Todo en soledad, en un ritual desamparado, en una "intemperie sin fin" -como dice Juan L. Ortiz-. ${ }^{4}$ Acompañado únicamente por esos seres, esos pueblos mitológicos. Como si el "monte" arrancara de este mundo a Eisejuaz, ahí, en el lugar llamado "Lo Que Se Ve":

${ }^{4}$ La intemperie sin fin, el libro de Oscar del Barco, toma su nombre de un verso del gran poeta entrerriano. 
Y se han ido todos. La oscuridad me recibió el corazón. Allí quedé, y descansé. Y me han levantado. He mirado el incienso aquel que está a la puerta de la casa que hice con mis manos. Un viento grande se alzó en ese momento y lo revolcó. Un viento lo enroscó, lo arrancó.

Esa casa y aquel lugar se llaman desde quel día: Lo Que Se Ve (Eisejuaz: 104).

\section{Bibliografía}

Dasso, María Cristina y Guadalupe Barúa, 2006, "El devenir de bienes e instituciones: el cebil y el shamanismo wichi”, Archivos, núm. 4-1, pp. 219-248.

Del Barco, Oscar, 1985, La intemperie sin fin, Universidad de Puebla, Puebla.

Flores, Enrique. "Eisejuaz: chamán (y relatos de la vida de Santos Aparicio)", 2020, Boletín de Literatura Oral, núm. 10, pp. 289307.

Gallardo, Sara, 2013, Eisejuaz, Martín Kohan (pról.), El Cuenco de Plata, Buenos Aires.

Pagés Larraya, Fernando, 1959, "La cultura del paricá”, Acta Neuropsiquiátrica, núm. 5, pp. 375-383.

, 1982, Lo irracional en la cultura, 4 vols., Fundación para la Educación, la Ciencia y la Cultura, Buenos Aires.

Tovar, Antonio, 1981, Relatos y diálogos de los matacos, Instituto de Cooperación Iberoamericana, Madrid. 